\title{
Rare Neonatal Digestive Surgical Emergencies at the Brazzaville University Hospital Center
}

\author{
Lucienne Irène Patricia Ondima ${ }^{1 *}$, Caryne Mboutol-Mandavo', Moïse Service Yanguedet ${ }^{1}$, \\ Didace Massamba Miabaou ${ }^{2}$, Jean-Claude Mieret ${ }^{1}$, Cardinale Princilia Okiemy Niendet ${ }^{1}$, \\ Gracia Christelle Ossete ${ }^{1}$, Peggy Dahlia Gallou Mawandza ${ }^{3}$, Neli Yvette Ngakengni4, \\ Gaston Ekouya Bowassa ${ }^{4}$
}

${ }^{1}$ Department of Pediatric Surgery, University Hospital Center, Brazzaville, Republic of Congo

${ }^{2}$ Department of Visceral Surgery, University Hospital Center, Brazzaville, Republic of Congo

${ }^{3}$ Department of Intensive care and Anesthesia, University Hospital Center, Brazzaville, Republic of Congo

${ }^{4}$ Department of Neonatology, University Hospital Center, Brazzaville, Republic of Congo

Email: *ondimairene@gmail.com

How to cite this paper: Ondima, L.I.P., Mboutol-Mandavo, C., Yanguedet, M.S., Miabaou, D.M., Mieret, J.-C., Niendet, C.P.O., Ossete, G.C., Mawandza, P.D.G, Ngakengni, N.Y. and Bowassa, G.E. (2020) Rare Neonatal Digestive Surgical Emergencies at the Brazzaville University Hospital Center. Open Journal of Pediatrics, 10, 463-473.

https://doi.org/10.4236/ojped.2020.103047

Received: June 16, 2020

Accepted: September 4, 2020

Published: September 7, 2020

Copyright $\odot 2020$ by author(s) and Scientific Research Publishing Inc. This work is licensed under the Creative Commons Attribution International License (CC BY 4.0).

http://creativecommons.org/licenses/by/4.0/

\begin{abstract}
The purpose of our study was to evaluate the morbidity-morality of rare neonatal digestive emergencies in order to improve their management. Observations: 7 newborns ranging in age from 6 hours to 3 weeks were treated for rare digestive pathologies between January 2013 and July 2017 (a period of 3 years and 6 months) in the Department of Pediatric surgery of Brazzaville University Center, Congo. Males were predominant (5 versus 2 females). Pathologies listed were: 1 antenatal volvulus of the small intestine, 1 annular pancreas and 5 gastric perforations. The average time of care in the operating room was 12 hours. The newborns were hospitalized in the pediatric surgery department in $28.6 \%$ of cases $(n=2)$, and $71.4 \%(n=5)$ in the neonatology department. The antenatal volvulus of the intestine and annulus pancreas were integrated into a nosologic entity named neonatal occlusion (NNO). The postoperative outcomes were simple for 4 patients (57.14\%) while 3 patients died immediately after surgery $(42.86 \%)$. Conclusion: Neonatal surgical emergencies are still difficult to manage in our context. The lack of knowledge of these rare pathologies, which delays their management, considerably increases morbidity-mortality. The critical analysis of this series highlights diagnostic and therapeutic difficulties particularly with gastric perforations, hence the interest of better popularization of pediatric surgery.
\end{abstract}

\section{Keywords}

Newborns, Emergencies, Rare, Surgery, Morbidity-Mortality, CHU, Brazzaville 


\section{Introduction}

Neonatal digestive surgical emergencies are congenital or acquired conditions of the newborn's digestive tube that require immediate surgical intervention [1] [2]. Digestive pathologies represent more than half of neonatal surgical emergencies [2]. With their average frequency estimated at $1 / 5000$ live births and their mortality rate still high according to the literature, they constitute a serious perinatal health problem [1] [3]. In developed countries, prenatal diagnosis and progress in neonatal intensive care anesthesia have profoundly modified management modalities, dramatically improving the prognosis of these pathologies and thus reducing their mortality rate. However, mortality remains very high $(43.1 \%$ case fatality rate) in the sub-Saharan African region [4].

The most frequent neonatal digestive pathologies are neonatal occlusions related to intestinal blockage or absence of intestinal transit downstream of the pylorus during the first month of life. Intestinal atresias of a portion of the intestine (duodenum, jejunum, ileo colon) affect mostly the small intestine. The principal warning signs are emesis, abdominal bloating and hydro-aerial levels on $\mathrm{x}$-rays (double bubble image without digestive aeration or central levels without colic aeration) with a surgical treatment of end to end anastomosis. Anorectal malformations are characterized by the absence of the anal orifice, the rectum with either a dead-end far from the perineum or a thin path called fistula. Alberto peñaclassifies them into anatomic forms depending on the gender and the anastomosis of the rectum. If the diagnostic is not done in the delivery room, warning signs will be those of the intestinal occlusion and the treatment dependent of the gravity of the anatomic form. Hirchsprung disease, also called congenital megacolon, is a functional anomaly of the terminal part of the intestine whose pathognomonic sign is the delay in the emission of the meconium beyond 24 hours. The classical manifestation is sub-occlusive array requiring nursing, the forms of intestinal still found indicate the establishment of a bypass colostomy [3]. Some of these pathologies are classified as rare because of their low frequency [5] [6], but they are a real management problem in the context of underdeveloped countries. The purpose of our study is to evaluate the morbidity-mortality of these rare neonatal digestive emergencies in order to improve their management.

\section{Observations}

\subsection{Observation 1}

A female newborn admitted two days after birth for abdominal bloating and greenish emesis noted a few minutes after birth before the first breastfeeding. The pregnancy was completed with 4 prenatal consultations without antenatal ultrasounds. Delivery was eutocic at an infantile and maternity center. Weight at birth was 3000 grams with an Apgar of 10/10, other anthropometric elements (height and head circumference) were not specified. Discharge from the center a few hours after delivery despite the persistence of greenish vomitus. An antibi- 
otic was administered. Given the persistence of abundant emesis and the impossibility of breastfeeding, the newborn was brought to the University Hospital Center of Brazzaville. On arrival, the newborn weighed 2800 grams, had a bloated abdomen. Parietal transparency revealed purplish loops and there was abundant vomiting during the examination (Figure 1). The decision to perform an emergency laparotomy for neonatal occlusion was made after standard biology report. No imaging was conducted.

We performed a mini supra and sub umbilical laparotomy. During surgery, a complete ischemia of the small intestine with a double coil presence was revealed (Figure 2 and Figure 3).

We conclude that it is an antenatal volvulus of the small intestine without a mesentery rotation anomaly. After unwinding the coil, we observed a pre-perforating zone of approximately $2 \mathrm{~cm}$ located at $10 \mathrm{~cm}$ of the ileo-caecal valve and a progressive and slow recoloring of the loops (Figure 4).

We performed a resection with end to end anastomosis and a rigorous washing and progressive reintegration of loops. The closing was done free of tension respecting different planes. Transfusion during and after surgery was necessary.
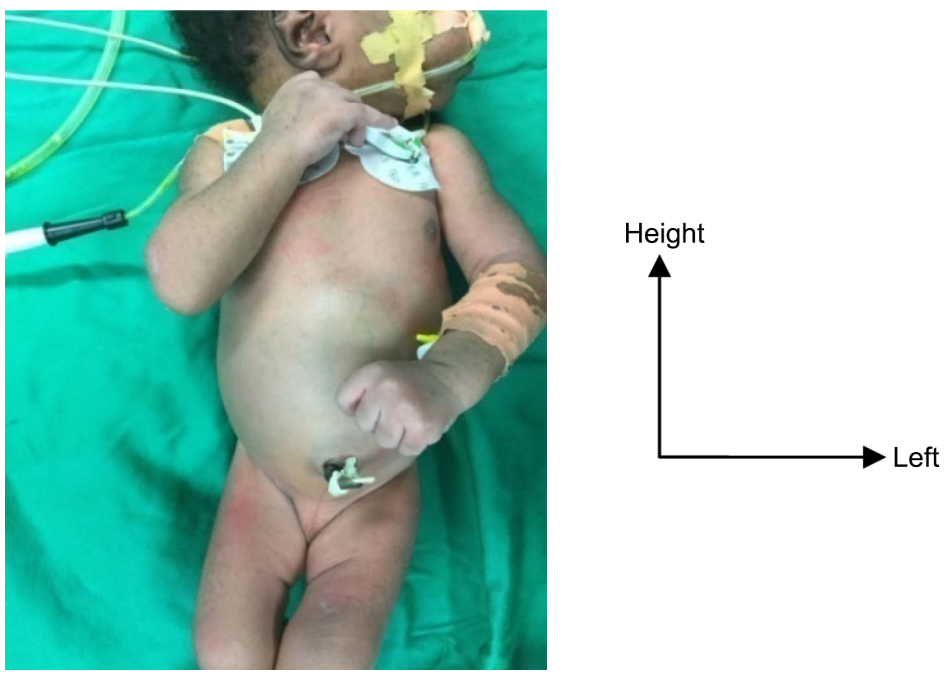

Figure 1. Newborn at day 2, ischemia through parietal transparency.
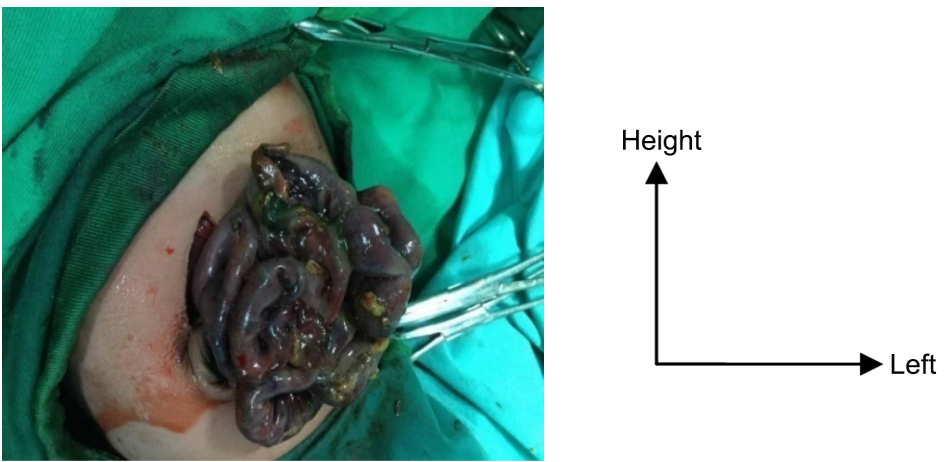

Figure 2. Volvolus of the small intestine: complete ischemia of the small intestine. 

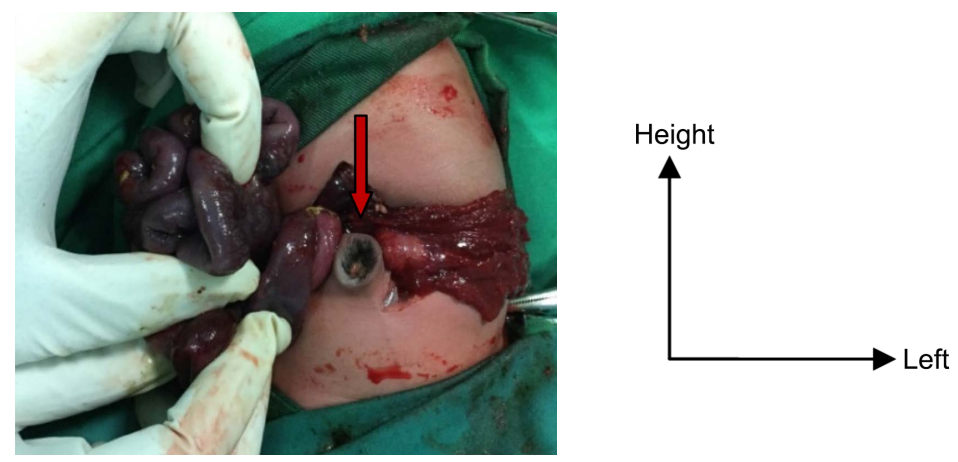

Figure 3. Double coil of the small intestine.
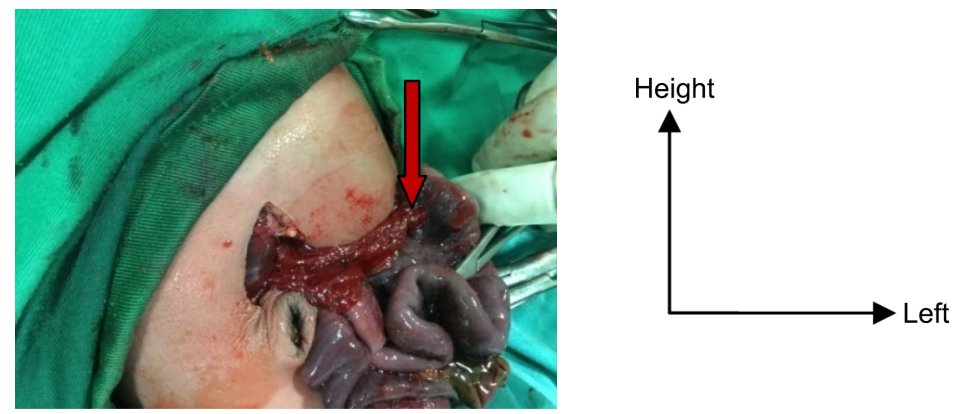

Figure 4. Progressive recoloring of loops.

The post-operative outcomes were simple with gradual recovery of maternal feeding six days post-surgery. Discharge from the hospital was done one-month post-surgery. Monitoring was regular with two and a half years follow-up post-surgery.

\subsection{Observation 2}

A male newborn was admitted 3 days after birth for early milky post-prandial vomiting. The pregnancy was well monitored with 6 prenatal consultations and 3 antenatal ultrasounds. None of the antenatal ultrasounds revealed any pathology. Delivery was by caesarian because of the late first pregnancy (mother aged 35) and took place in a private clinic. Anthropometric parameters were: birth weight 2750 grams, Apgar 10/10, height $35 \mathrm{~cm}$ and head circumference $35 \mathrm{~cm}$. At examination, the newborn was in overall good state presenting milky emesis, a flat, flexible and trough-like abdomen with peristaltic waves (signs of struggle) in the epigastric quadrant (Figure 5).

Imaging, namely AP thoraco-abdominal radiography (x-rays) that was performed at 2 days interval had shown a double bubble image evoking duodenal obstacle (Figure 6 and Figure 7).

It was a neonatal occlusion with flat abdomen. Surgery was indicated and carried out the fifth day of life after pre-operative management by intensive care and neonatology teams. We performed a supra and sub umbilical laparotomy, during which no anomaly was detected due to lack of knowledge of the diagnosis. We observed improvement of symptomatology but four days after surgery, 

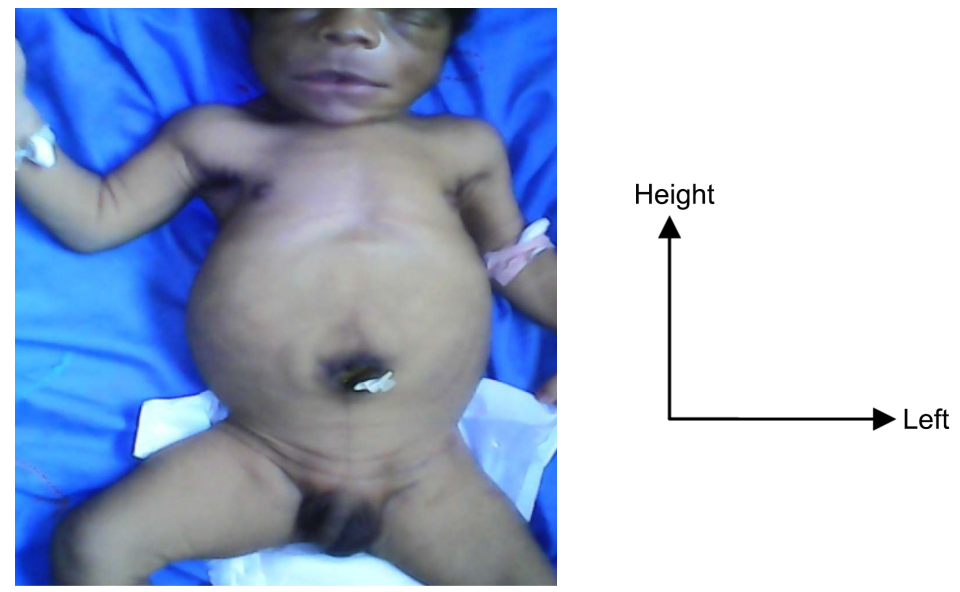

Figure 5. Newborn at day 3 presenting with flat abdomen and sign of struggle.
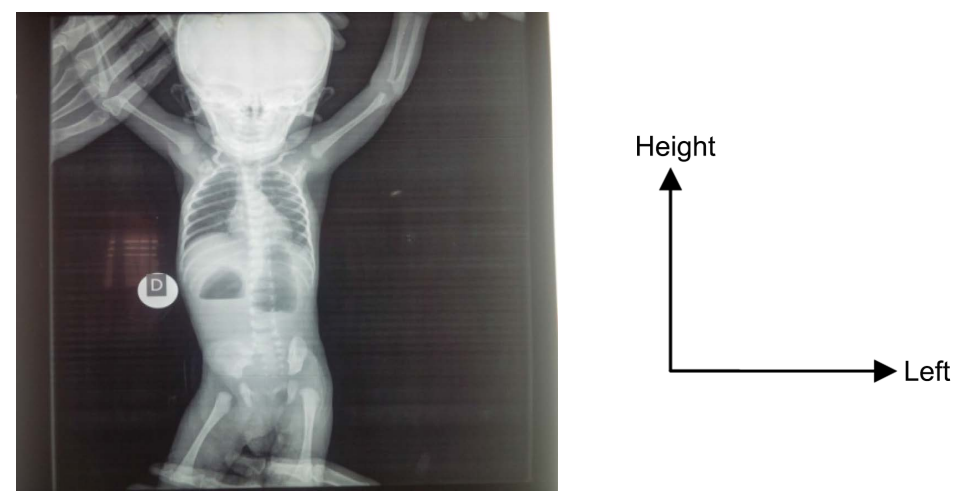

Figure 6. Radiography $n^{\circ} 1$ : double bubble image.
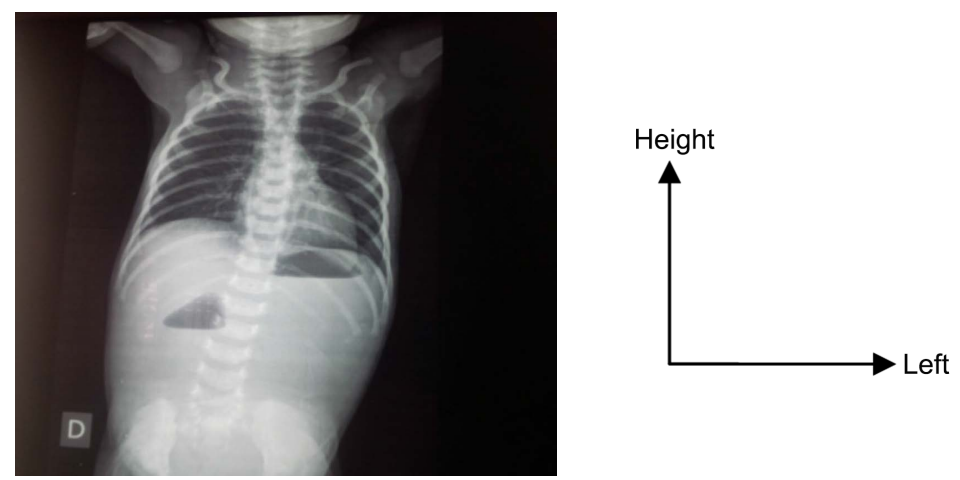

Figure 7. Radiography $n^{\circ} 2$ : double bubble image.

we noted a resurgence of emesis. The radiography performed was identical to the first ones, indicating repeat surgery, which was performed in the presence of the Head of the surgery department. We identified a pancreatic strip surrounding the second portion of the duodenum and considered annulus pancreas as the working diagnosis (Figure 8). We carefully carried out surgical bypass of the annulus pancreas with duodeno-duedenostomy allowing to span the obstacle (Figure 9). 

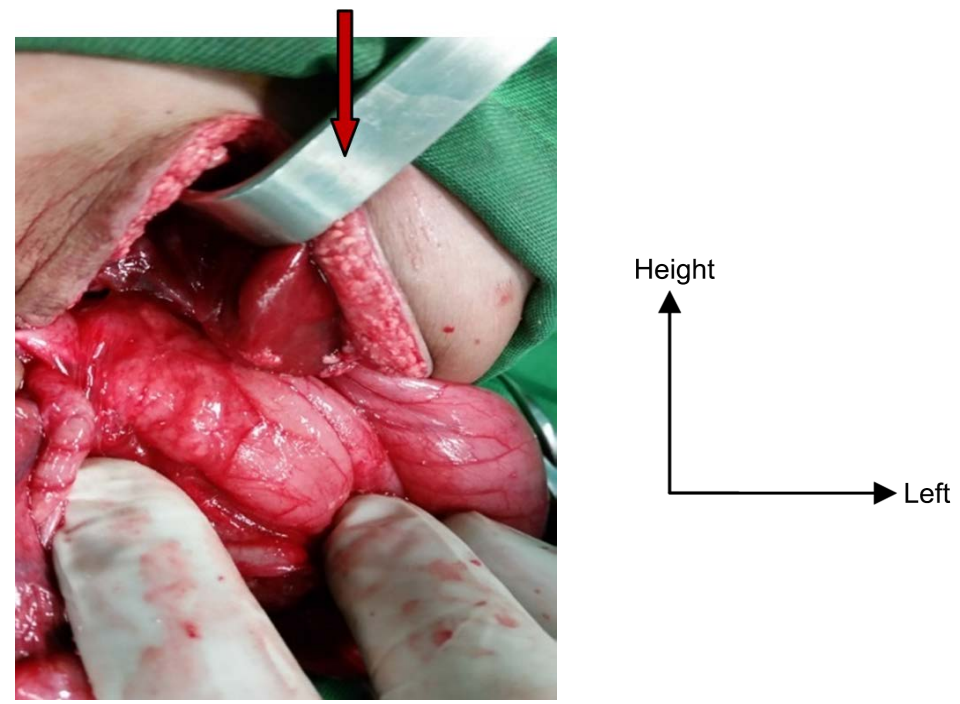

Figure 8. Pancreatic strip.
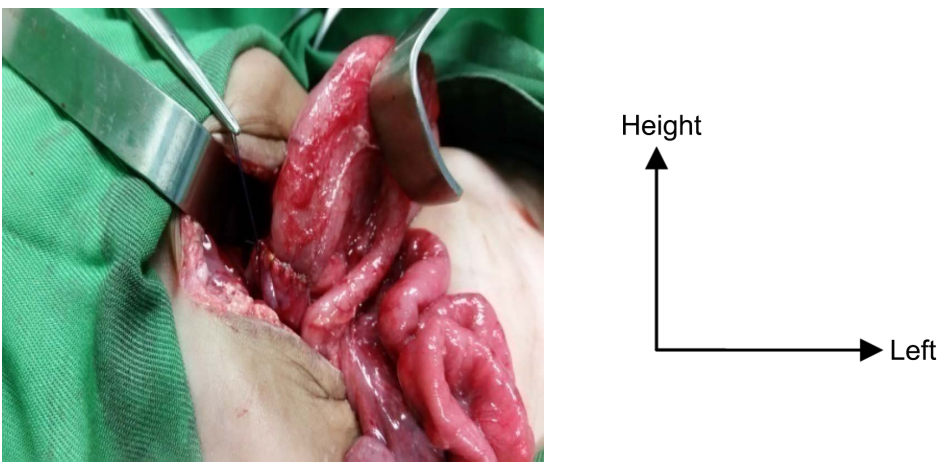

Figure 9. By-pass spanning annulus pancreas.

The postoperative management was straightforward with recovery of artificial eating habits the fifth day post-surgery. Discharge from the hospital was allowed ten days after surgery. Monitoring was regular together with the pediatrician, with a follow-up of four and half years post-surgery.

\subsection{Observations $3,4,5,6,7$}

The five patients were all managed by the neonatology unit for neonatal infections and/or premature birth. Four were male with average age being twelve days (range 8 - 25 days). None of the pregnancies had been monitored regularly, with less than three antenatal consultations. Four deliveries were dystocic among whom one was homebirth. The average weight was 1500 grams and four were premature births (34 - 36 weeks). They all presented abdominal bloating with greenish residues. The indication for the implantation of a permanent nasogastric tube was determined as soon as greenish emesis was seen. Anterior-posterior thoraco-abdominal radiographs carried out for all patients highlighted interhepato-diaphragmatic gaseous crescents.

Surgery for all patients was indicated and carried out with an average man- 
agement delay of 24 hours, because of prematurity and metabolic disorders. Accessibility was in all the cases, a supra and sub umbilical laparotomy. We found gastric perforations during surgery in all five patients of whom three cases (60\%) were large perforations (open book) (Figure 10) and two cases were point like perforations.

We revitalized banks with a $4 / 0$ vicryl suture (Figure 11) followed by a rigorous abdominal cleansing.

We associated drainage of the abdominal cavity for the three large perforations. The postoperative outcomes were poor for three cases, with death within 72 hours among ( 2 large perforations and 1 point like perforation). Outcomes were good for the remaining two cases. Maternal breastfeeding was introduced progressively on the sixth day post-surgery. Discharge from the hospital was authorized fifteen days after surgery with regular follow-up. The average follow-up time period of three years and half is satisfactory.

All these newborns have received proton pump inhibitor treatment.
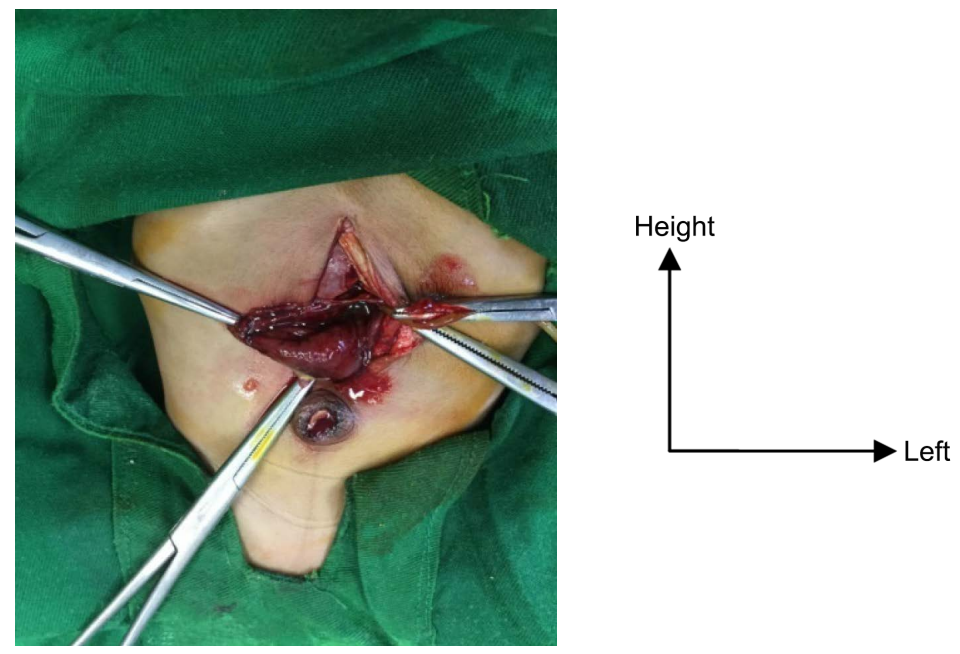

Figure 10. Large gastric perforation.
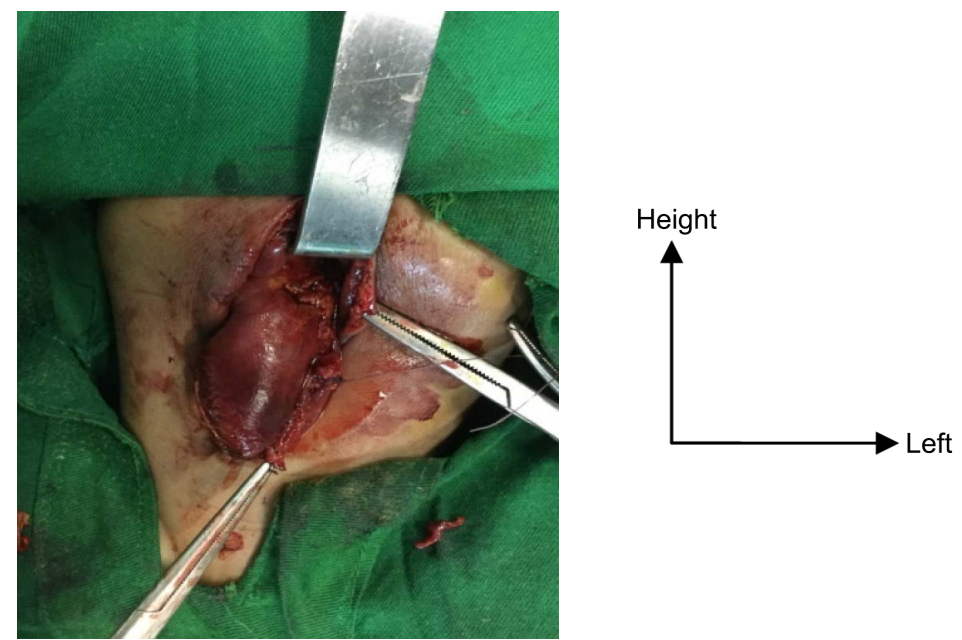

Figure 11. Gastric suture after revitalization of banks. 


\section{Discussion}

Our study's aim was to consider how to reduce morbidity-mortality due to congenital or acquired neonatal digestive emergencies. We were interested in a particular group of these pathologies, specifying the epidemiologic, clinical, therapeutic and evolving aspects. Our study, based on seven cases represents certainly a small cohort, but it takes into account certain rare pathologies of difficult diagnosis and management in our context. It is not comparable to case series in contexts where advanced medical technology in antenatal diagnosis, neonatal surgery and neonatal intensive care [7], has allowed a spectacular decrease of the mortality, going from $50 \%$ to $10 \%$ in a decade.

In Sub-Saharan Africa, most studies take into account all neonatal emergencies [2] [3] [8] [9] [10] [11], others on all digestive pathologies [1], or on neonatal occlusions [12]. Our 5\% annual neonatal surgery activity is dominated by digestive pathology ( $60 \%$ of cases). This number is close to that of the literature in which digestive pathologies come first among all neonatal emergencies. Midekor [9] at the University Hospital Center of Cocody Abidjan Côte d'Ivoire finds 48.75\%, Mieret [2] in Youpougon, Abidjan 58.2\% of cases, Boumas [11] in Libreville $73.8 \%$ (digestive tube and parietal emergencies) and Mady-Goma in Brazzaville $74.2 \%$.

None of these studies addresses a series of rare pathology as ours has listed. However like our study, they concern newborns from 0 to 28 days [2] [3] [11] for some and from 1 to 30 days for others [12]. The sex predominance in our series is male with a sex ratio of 2.5 , it varies depending on authors, with a sex ratio of 0.8 for Mieret [2], 0.9 for Boumas [11], 1.4 for Midekor [9] and 1.5 for Cikomola [8]. Our 12 hours average management delay surpasses by far that of African series due to scarcity and seriousness of the pathologies. Management delay also varies depending on authors Boumas [11] 4.9 days. The pathologies in different studies include few digestive surgical emergencies (3.3\%) [8] and neonatal emergencies (0.07\%) [9].

Barry [1] in Bamako-Mali, found 4 digestive peritonitis cases (11\%) without any precision of location, Boumas [11] in Libreville 9 cases $(0.2 \%)$ of peritonitis without further precision. Mady-Goma's study in Brazzaville [3] with 7 cases of gastric perforation is close to our series of 5 cases, these numbers much higher to those of numerous studies with 1 to 2 cases [13]-[18] can only be explained by the possibility of an iatrogenic cause. All factors favoring idiopathic perforation described in the literature are found in our study namely, poor pregnancy monitoring with less than 3 prenatal consultations for 4 of 5 newborns, 4 dystocic deliveries out of 5 , one of which was homebirth, prematurity for 4 cases, hospital stay for all 5 cases and neonatal infections for 2 cases. We could not determine the etiology of these idiopathic or iatrogenic perforations, the latter can be attributed to intermittent tubing in neonatology services, in search of gastric residues prior to any breastfeeding.

The antenatal volvulus and the annular pancreas are rare in African series and 
their management remains delicate even in the West. The antenatal volvulus is presently, with progress in the intensive care, managed by antenatal surgery, because it remains the cause of high neonatal mortality rate and could be due to anti-kell [19] allo-immunization, the single case of our series is of positive evolution.

The annular pancreas is a rare congenital anomaly, in which the pancreatic tissue surrounds the second portion of the duodenum, causing duodenal occlusion. About $2 / 3$ of affected cases are asymptomatic. In those $2 / 3$ cases, symptoms are most present during neonatal period, but their manifestation can be delayed until adulthood. The diagnosis of annulus pancreas in the neonatal period can be suggested by an anterior-posterior radiography of the abdomen showing the same sign of the double bubble as that observed in duodenal atresia. The treatment of the annulus pancreas is surgical bypass of the annulus pancreas with duodeno-duodenotomy, duodeno-jejunostomy or gastro-jejunostomy [6] [7]. In our case, we carried out a surgical bypass of the annulus pancreas with duodeno-duodenostomy. Our single case is of positive outcome.

The postoperative outcomes were simple for 4 patients (57.14\%), with a high morbidity because the postoperative stay was on average 15 to 30 days.

Our mortality rate of $42.86 \%$ is similar to that of Mouafo in Yaounde with $42.1 \%$ of death cases in the neonatal digestive emergencies.

\section{Conclusion}

The University Hospital Center of Brazzaville is the only reference center for the management of neonatal surgical emergencies in the Republic of Congo. The anesthesia-intensive care team is still common for children and adults. Analyzing our results namely 7 cases of rare digestive pathologies, we experience difficult management with a very high mortality rate of $42.86 \%$. We estimate that the improvement of the vital prognosis of all neonatal emergencies, particularly those listed in our study requires the implantation of a modern neonatal intensive care setting and continuing training of care givers enabling early diagnosis and management. This will help decrease difficulties of underdeveloped countries, already depicted in different African series.

\section{Conflicts of Interest}

Authors declare they have no conflicts of interest.

\section{References}

[1] Abdoulaye, B. (2002) Thesis on Neonatal Digestives Surgical Pathologies at Gabriel Toure Hospital Faculty of Medecin, Pharmacy and Odontostomatology. University of Bamako, Bamako.

[2] Claude, M.J., Serge, K.Y.G., Baptiste, Y.J. and Gaudens, D.A. (2018) Neonatal Surgical Emegnecies in the Service of Pediatric Surgery. University Hospital Center of Youpougon, Marien Ngouabi University, Brazzaville.

[3] Goma, M. and Rosine, C. (2013) Neonatal Sugical Emergencies at the University 
Hospital Center of Brazzaville. Thesis Faculty Health Sciences, Marien Ngouabi University, Brazzaville.

[4] Mouafo Tambo, F.F., Chiabi, A., Ngowe Ngowe, M., Ze Mikande, J., Andze, O.G. and Sosso, M.A. (2011) Neonatal Surgical Emergencies Mortality at HGOPY. Médecine Tropicale, 71, 206-207.

[5] Bouasker, I., Hani, M.A, Ben Achour, J., Bedoui, R., Najah, H., Zoghlami, A., Najah, N., Dziri, C. (2008) Annular Pancreas in Adults: A Case Report. Biologic and Clinical Gastroenterology, 32, 924-925. https://doi.org/10.1016/j.gcb.2008.04.029

[6] Meyiz, H., Ibrahimi, A. and Elyousfi, M. (2018) Symptomatic Annulus Pancreas in the Adult: Case Report. IOSR Journal of Dental and Medical Sciences, 17, 80-82.

[7] Kammoun, H., Jallouli, M., Trigui, L., Gargouri, A., Regaig, R., Ben Amar, H. and Mhiri, R. (2007) Localised Intestinal Perforation in Neonate: Distinct Entity or Focal Form of Necrotising Enterocolitis. Journal de Pédiatrie et de Puériculture, 20, 206-208. https://doi.org/10.1016/j.jpp.2007.07.004

[8] Fabrice, C.G., Alain, N.K., Aline, B.N., Yvette, L.B. and Jeff, K.M. (2016) Neonatal Surgical Emergencies at Provincial General Reference Hospital of Bukavu Democratic Republic of Congo. Pan African Medical Journal, 24, 219. https://doi.org/10.11604/pamj.2016.24.219.8495

[9] Midekor, G.K.A., Kouassi, D.A.S.L., Ake, Y.L., Kouao, J.-P., Bonny, R. and Moh, E.N. (2016) Neonatal Surgical Emergencies in the pediatric Surgery Service of the CHU of Cocody. Revue Internationale des Sciences Médicales, 18,161-164.

[10] Keita, M., Diallo, M.S.A., Keita, A.K. and Balde, I. (2006) Neonatal Surgical Emergencies in the Service of Pediatric Surgery of the CHU of Donka. Mali Médical, 4, 16-20.

[11] Bournas, N., Minko, J.I., Mba Ella, R., Mba Meyo, J. and Ondo Ndong, F. (2017) Epidemiologic Profile of Neonatal Surgical Emergencies of the Pediatric Surgery Service of the CHU of Libreville. Bulletin Médical d Owendo, 15, 17-20.

[12] Takongmo, S., Binam, F., Monebenimp, F., Simeu, C.H. and Malonga, E.E. (2000) Neonatal Occlusions in the Service of General Surgery in Yaounde. Médecine d Afrique Noire, 47, 153-156.

[13] Ouedraogo, I., Kabore, R., Napon Madina, A., Ouedraogo, F., Ouangré, E. Bandré, E., Tapsoba, W.T., Sore, O., Beré, B., Kaboré, R.A.F. and Wandaogo, A. (2015) Epidemiology of Neonatal Surgery Emergencies in Ouagadougou. Archives de Pédiatrie, 22, 130-134. https://doi.org/10.1016/j.arcped.2014.11.017

[14] Rakoto-Ratsimba, H.N., Rakotoarisoa, B., Samison, L.H., Belalahy, V. and Ranaivozanany, A. (2004) Spontaneous Gastric Perforation in a Neonate: A Case Report. Archives de Pédiatrie, 11, 1067-1069. https://doi.org/10.1016/j.arcped.2004.05.013

[15] Tembely, S., Dieth, A.G., Yaokreh, J.B., Soro, L., Odehouri-Koudou, T.H., Kouame, R.N., Kouamé, Y.G.S., Kouamé, D.B., Ouattara, O., Da Silva-Anoma, S. and Dick, K.R. (2013) Peritonitis by Gastric Perforation of the Newborn. Revue Internationale des Sciences Médicales, 15, 104-107.

[16] Peggy, D., Anne-Sophie, T., Marie-Gabrielle, G, Thierry, P., Corinne, J.-P. and Bernard, G. (2003) Idiopathic Gastric Perforation of the Newborn: 2 Cases Report. Biologic and Clinical Gastroenterology, 27, 1160-1162.

[17] Naji, A., Elkarout, Y. and Benajiba, N. (2015) Spontaneous Neonatal Gastric Perforation: Case Report. Pan African Medical Journal, 21, Article: 61. https://doi.org/10.11604/pamj.2015.21.61.5560 
[18] Dimitri, K.N., et al. (2018) Spontaneaous Gastric Perforation: Case Report. Pan African Medical Journal, 30, Article: 72. https://doi.org/10.11604/pamj.2018.30.72.13205

[19] Leport, M., Dupont-Chauvet, P., Guillois. B. and Volvulus, A. (2015) The Stenotic Small Intestine Consecutive to Ananti-Kell Allo-Immunization. Pediatric Archives, $22,233-371$. 